\title{
Impact of Climate Change Heating and Cooling Energy Use in Buildings in the United States
}

\author{
Haojie Wang ${ }^{1}$ and Qingyan Chen ${ }^{2,1^{*}}$ \\ ${ }^{1}$ School of Mechanical Engineering, Purdue University, West Lafayette, IN 47907, USA \\ ${ }^{2}$ School of Environmental Science and Engineering, Tianjin University, Tianjin 300072, China \\ *Tel. (765)496-7562, Fax (765)494-0539, Email: yanchen@purdue.edu
}

\begin{abstract}
Global warming has drawn great attention in recent years because of its large impact on many aspects of the environment and human activities in buildings. One area directly affected by climate change is the energy consumption for heating and cooling. To quantify the impact, this study used the HadCM3 Global Circulation Model (GCM) to generate weather data for future typical meteorological years, such as 2020, 2050, and 2080, for 15 cities in the U.S. based on three $\mathrm{CO}_{2}$ emission scenarios. The method was validated by comparing the projected TMY3 data using HadCM3 with the actual TMY3 data. By morphing method, the weather data was downscaled to hourly data for use in building energy simulations by EnergyPlus. Two types of residential buildings and seven types of commercial buildings were simulated for each of the 15 cities. This paper is the first to systematically study the climate change impact on various types of residential and commercial buildings in all 7 climate zones in the U.S. through EnergyPlus simulations and provide weighted averaged results for national-wide building stock. We also identified geographical dependency of the impact of climate change on future energy uses. There would be a net increase in source energy consumption by the 2080s for climate zones 1-4 and net decrease in climate zones 6-7 based on the HadCM3 weather projection. Furthermore, this paper investigated natural ventilation performance in San Francisco, San Diego, and Seattle with improved natural ventilation model. We found that by the 2080s passive cooling would not be suitable for San Diego because of global warming, but it would still be acceptable for San Francisco and Seattle.
\end{abstract}

Keywords: climate change; building energy use; global warming; EnergyPlus; natural ventilation 


\section{Introduction}

Climate change and global warming have been of major concern to the public because of the potential threat to the ecosystem and living environment. The Intergovernmental Panel on Climate Change (IPCC) has projected that the annual temperature increase from the 1960s to the 2100s will be in the range of 1 to $7 \mathrm{~K}$ under various $\mathrm{CO}_{2}$ emission scenarios [1]. In addition to temperature change, humidity, wind, and solar radiation are also likely to change over the years because of higher $\mathrm{CO}_{2}$ emissions [2]. Climate change will have a large impact on building energy use for heating and cooling because of the change in outdoor conditions [3, 4]. In 2010, building energy consumption accounted for $41 \%$ of the total prime energy use in the U.S., and about $50 \%$ of the building energy consumption was for space heating and cooling [5]. Energy consumption levels for cooling and heating are expected to increase and decrease, respectively, as a result of global warming [6]. However, the impact of climate change on heating and cooling energy use in different locations will vary because of their different climates [3,7]. A detailed analysis of heating and cooling energy use in the future is needed to better understand the impact of climate change on building energy consumption.

A reasonable prediction of the future climate is the first requirement for an energy analysis of buildings. The most comprehensive models for future climate prediction are Atmosphere-Ocean Global Circulation Models (AOGCMs) [1]. Among the various AOGCMs, HadCM3 has been widely used for predicting future climates [8-10] because of its higher ocean resolution, which enables it to generate reasonable predictions without the need for artificial flux adjustment [11].

In early studies, the degree day method was widely used with future weather data to determine the impact of climate change on building energy consumption $[4,12]$. Degree day analysis uses the balance point temperature of a building, that at which the building does not require either cooling or heating. The choice of balance point temperature can be different for each region and each type of building [13]. The Heating Degree Days (HDDs) and Cooling Degree Days (CDDs) are calculated hourly over a year as

$$
\mathrm{HDD}=\sum_{1}^{365} \sum_{1}^{24}\left(T_{b}-T_{o}\right)^{+} / 24
$$




$$
\mathrm{CDD}=\sum_{1}^{365} \sum_{1}^{24}\left(T_{o}-T_{b}\right)^{+} / 24
$$

where $T_{b}$ is the balance point temperature and is usually assumed to be $18.3{ }^{\circ} \mathrm{C}\left(65^{\circ} \mathrm{F}\right)$ for the sake of simplicity [13]. $T_{o}$ is the outdoor daily temperature. The plus sign means that only positive values will be used, and all negative values are treated as zero. This method can provide a quick estimate of the impact of climate change on buildings. However, since solar radiation, humidity, and building characteristics such as thermal mass are not considered in degree day analysis, studies have often found that this method would lead to large deviations as compared to energy simulations [14]. Therefore, hour-by-hour energy simulation is better for studying the impact of climate change on heating and cooling energy consumption in buildings.

Furthermore, the impact of climate change will vary greatly according to geographical region and building types [3,6]. Many residential buildings in coastal areas and mild climate zones do not have air-conditioning systems and depend solely on natural ventilation for cooling [18]. These differences among HVAC systems will lead to variations in the impact of climate change. Table 1 lists past literature that studied the impact of climate change on building energy consumption. It shows that most of studies are regional based and only focus on a few types of buildings, thus could not predict the general impact of climate change on the whole building stock. Furthermore, the results from each author varied greatly and are not comparable because the types of the building and climate characteristics were not systematically classified.

Therefore, to systematically study the impact of climate change on the whole building stock in the U.S., this paper reports our findings of the change in cooling energy use in buildings in 15 different U.S. cities located in seven climate zones as described in ASHRAE 90.1 [25] by 2080s. The energy simulations in each city included two types of residential buildings and seven types of commercial buildings. This study also evaluated natural ventilation performance in San Francisco, San Diego, and Seattle, where it is widely used in residential buildings. The study addresses the impact of climate change across the nation on heating and cooling energy consumption. 


\section{Methodology}

\subsection{Future weather data}

This study used the HadCM3 model to project future climate change for three different $\mathrm{CO}_{2}$ emission scenarios (A1F1: high emission; A2: medium emission, and B1: low emission) [1]. This model contain coupled the atmosphere model HadAM3, with a horizontal resolution of $2.5^{\circ}$ latitude by $3.75^{\circ}$ longitude, and oceanic model HadOM3 with horizontal resolution of $1.25^{\circ}$ by $1.25^{\circ}$. The two component exchanged information daily and would conserve heat and water mass flux but since momentum fluxes are interpolated between the atmosphere and ocean grids, it is not conserved precisely. Nevertheless, Johns et al. [10] have shown this imbalance did not affect the results significantly. HadCM3 provides the monthly change in dry-bulb temperature, diurnal temperature variation, relative humidity, wind speed, and solar radiation, which have a major impact on the building heating and cooling load and can be found on IPCC website for three emission scenarios (http://www.ipcc-data.org/sres/hadcm3_download.html). Since the grid point of HadCM3 might not coincide exactly at the locations studied in this paper, we use linear interpolation from the four closest grid points. Moreover, another problem with HadCM3 model and other AOGCMs is that they only provide monthly data, which is insufficient for hourly energy simulation. We therefore used a morphing method to down-scale the monthly changes to hourly changes and then applied the changes to the current weather data [15-17]. The general formula for calculating future hourly weather parameter $x$ includes a stretching factor and shifting to the original weather parameter $x_{0}$ as

$$
x=x_{0}+\Delta x_{m}+a_{m}\left(x_{0}-\left\langle x_{0}\right\rangle_{m}\right)
$$

where $x_{0}$ is the current hourly weather data, $\Delta x_{m}$ the monthly mean change obtained from HadCM $3, a_{m}$ the stretching factor, and $\left\langle x_{0}\right\rangle_{m}$ the monthly mean of the current weather data. A simple verification of the monthly mean of from Eq. (3) (taking monthly mean value, denoted by \langle\rangle$_{m}$, on each side of Eq.3, yields $\left.\langle x\rangle_{m}=\left\langle x_{0}\right\rangle_{m}+\Delta x_{m}\right)$ showed that this method conserves the original monthly mean change obtained from the HadCM3 model.

For the future hourly dry-bulb temperature, the stretching factor $a_{m}$ in Eq. (3) is calculated as 


$$
a_{m}=\frac{\Delta \operatorname{TMAX}_{m}-\Delta \operatorname{TMIN}_{m}}{\left\langle T_{d b 0, \max }\right\rangle_{m}-\left\langle T_{d b 0, \min }\right\rangle_{m}}
$$

where $\triangle T M A X_{m}$ and $\triangle T M I N_{m}$ are the monthly mean changes in diurnal temperature in the future, which were obtained from the HadCM3 model, and $\left\langle T_{d b 0, \max }\right\rangle_{m}$ and $\left\langle T_{d b 0, \min }\right\rangle_{m}$ are the monthly mean changes in diurnal temperature under current weather conditions. For humidity and wind speed, the data provided in HadCM3 are changes in percentage, and thus only the stretching factor is applied as

$$
x=\left(1+\Delta x_{m} / 100\right) x_{0}
$$

where $x$ is the future wind speed or relative humidity, $\Delta x_{m}$ the monthly mean change (in percentage) obtained from the HadCM3 data, and $x_{0}$ the current weather data. For solar radiation, only the stretching factor is used because the shifting would add solar radiation at night, which is unrealistic. The solar irradiance on horizontal surface $I_{h}$ is calculated as

$$
I_{h}=\left(1+\Delta I_{h, m} /\left\langle I_{h, 0}\right\rangle_{m}\right) I_{h, 0}
$$

where $I_{h}$ is the future hourly solar irradiance, $\Delta I_{h, m}$ the monthly mean change in solar irradiance, and $I_{h, o}$ the current hourly solar irradiance.

This study used six typical meteorological year (TMY) data sets, including three historical TMY data sets: TMY (data from 1948-1980), TMY2 (1961-1990), and TMY3 (1991-2005), which were obtained from the National Renewable Energy Laboratory. (For the sake of simplicity, the figures in this paper use the median year during the period when the weather data was collected to denote TMY, TMY2, and TMY3, i.e. TMY is denoted as 1964, TMY2 as 1976, and TMY3 as 1998.) The future TMY data for the 2020s, the 2050s, and the 2080s was generated by Eqs. (4)(6), and we then applied the hourly changes to TMY3. Table 2 lists the 15 cities investigated in this paper and their corresponding climate zones.

This study also conducted a simple degree day analysis and compared the results with energy simulations. The balance point used in this study was $18.3^{\circ} \mathrm{C}\left(65^{\circ} \mathrm{F}\right)$ [13] for all the cities. The heating degree days and cooling degree days were calculated using Eqs. (1) and (2). 


\subsection{Building model}

This study investigated nine types of buildings with the EnergyPlus 8.1 program [26] and the geometry was rendered by Sketchup. In order to determine the impact of climate change on the entire building stock in the U.S., this study weighted the energy intensity for each type of building by the floor area of that type as a percentage of the total floor area in the U.S. building stock. Table 3 lists the types of buildings studied, their total floor areas in the U.S., and important building model information. The total outdoor air ACH is the sum of infiltration and mechanical ventilation based on ASHRAE Standards 62.1 [27] and 62.2 [28]. Figure 1 shows the rendering of the building models used in the EnergyPlus program.

Table 4 shows the building envelope and internal load information for the model. The commercial building models used in this investigation are from Thornton et al. [29] and represent typical commerical buildings in the U.S. The residential building models used are from Mendon et al. [30]. The commercial building envelope insulation is based on ASHRAE 90.1 [25] Table 5.5-1 to 5.5-7; the internal load, including people, lighting, plug load are based on space types from Thornton et al. [29] for commerical buildings and Mendon et al. [30] for residential buildings; the heating/cooing setpoints are set as $21 / 24{ }^{\circ} \mathrm{C}$ with $2.7{ }^{\circ} \mathrm{C}$ setback during unoccupied hours. The residential building envelope insulation are designed to meet the minimum requipments set by Table 5.2 in ASHRAE 90.2 [31] for each climate zone. Because many of the residential buildings in San Francisco, San Diego, and Seattle do not have airconditioning systems [18], this study also investigated scenarios with natural ventilation as the cooling strategy for single-family houses in these three cities by switching the mechanical system module to the natural ventilation module. The ventilation rate for natural ventilation was calculated on the basis of a model developed by Wang and Chen [32] and was implemented into EnergyPlus. The control strategy for natural ventilation was to keep the window open when the outdoor temperature was between 16 to $26^{\circ} \mathrm{C}$, which is $2-4^{\circ} \mathrm{C}$ lower than the $90 \%$ acceptable indoor temperature defined by ASHRAE adaptive comfort model [29] which is used to meet the cooling load in the building.

The weighted building heating and cooling energy intensities $I$ for the nine types of buildings were calculated as 


$$
I=\sum_{i=1}^{9}\left(\frac{E_{i}}{A_{\text {simu }, i}} \cdot \frac{A_{\text {total }, i}}{A_{\text {total }}}\right)
$$

where $E_{i}$ is the energy for cooling or heating for building type $i$ calculated by EnergyPlus, $A_{\text {simu, } i}$ the floor area of the building model for building type $i$ in EnergyPlus, $A_{\text {total, }}$ the total floor area in the U.S. building stock for building type $i$, and $A_{\text {total }}$ the total floor area of all types of buildings in the U.S.

\section{Results and Discussion}

\subsection{Weather characteristics}

The first step of this study was to generate weather data for the future by using the model proposed in the previous section on the basis of the current TMY3 data. In order to validate the accuracy of HadCM3 model, we first applied this model to TMY2 data to obtain the predicted TMY3 data and compared them with the actual TMY3 data. Figure 2 shows the comparisons of monthly dry-bulb, dew point temperature and global horizontal solar radiation intensity, which are the major inputs in energy simulations. The results showed that for dry-bulb and solar radiation, the prediction is generally within the $10 \%$ error, but for humidity, i.e. the dew point temperature, we observed some large deviation near $0{ }^{\circ} \mathrm{C}$. One reason is that the humidity ratio at low temperature is very small, thus even a small absolute deviation will result in large relative deviation. Nevertheless, since humidity only impact the building latent cooling load, which usually occurs at above $12{ }^{\circ} \mathrm{C}$, the deviation at low dew point temperature would not have impact on the building energy prediction.

Figure 3(a) shows the change in annual temperature in the four selected cities between the 1960s to the 2080s under the medium $\mathrm{CO}_{2}$ emission scenario (A2). The first three weather data points are the actual data for a typical meteorological year. The annual temperature in each weather data set was compared to the 1964 (TMY) data to calculate the temperature change. The results indicate that the temperature change varies greatly with location. By 2080, the changes are in the range of $3-6^{\circ} \mathrm{C}$ for the four cities, which agrees with the IPCC report [1]. Furthermore, Figure 3(a) shows that the temperature changes more rapidly after 2000. This trend is caused by the 
rapid growth in population and the slow rate of technology change as described in the A2 emission scenario [1].

Figure 3(b) compares the future weather data under the three $\mathrm{CO}_{2}$ emission scenarios for New York City. The annual temperature change from 1964 to 2080 under the high $\mathrm{CO}_{2}$ emission scenario (A1F1) would be $6^{\circ} \mathrm{C}$, while under the low emission scenario (B2) it would be only $3^{\circ} \mathrm{C}$. By simulating the three scenarios, we cover a wide range of possible levels of climate change. Even if there were large uncertainties in the HadCM3 model, our energy simulations would account for the potential best- and worst-case scenarios.

\subsection{Energy analysis}

This section discusses the results of our EnergyPlus simulations. Our study conducted more than 2000 simulations covering 15 cities, nine types of buildings, three historical weather data sets, and three future weather data sets under the three emission scenarios. We assumed that the building stock structure is the same in every city studied in this paper and remain unchanged throughout the simulation period, namely, each type of building would have the same floor area fraction to the total building stock in the U.S. in all the cities studied in this paper. The energy intensity for each city was weighted by the floor area fraction for each type of building as described in Eq. (7).

Figure 4(a) shows the changes in site energy intensity for cooling and heating by the 2080s as compared to the 1960s. Typically, because of global warming, the energy intensity for cooling for all the cities would increase under the three $\mathrm{CO}_{2}$ emission scenarios, and the energy intensity for heating would decrease. However, as climate characteristics vary from city to city, the magnitude of change also varies. In hot climates, the change in cooling energy intensity will be much larger than that for heating, as seen in Houston, Miami, and San Diego. In cold or very cold climates, the decrease in site energy for heating will largely exceed the increase in site energy for cooling.

In this study, the energy sources were natural gas for heating and electricity for cooling. Since electricity has more exergy than natural gas in one unit of energy, it is unreasonable to compare 
the cooling and the heating energy directly. Instead, the site energy should be converted to source energy and used to calculate the net change of energy use for cooling and heating. Deru and Torcellini [34] estimated that the national average site-to-source conversion factors were 3.365 for electricity and 1.092 for natural gas. Site-to-source conversion is largely dependent on the energy source structure in the U.S., and it may become lower for electricity in the future, as the efficiency of power plants improves and renewable energy is more widely used. However, because information about future conditions was not available, we assumed the site-to-source factor to be constant from the 1960s to the 2080s.

After applying the conversion factor and calculating the total source energy for both heating and cooling, we obtained the net change in source energy consumption by the 2080s. Figure 4(b) shows the change in energy intensity for 15 cities by 2080 as compared to 1964 (TMY) weather data under three emission scenarios. Positive values in Figure 4(b) indicate that the source energy use for heating and cooling would increase by the 2080s, while negative values indicate a decrease. The figure shows a net reduction in energy use by heating and cooling sources for cities in cold and very cold climates, i.e. Climate Zones 6 and 7. Some cities in Climate Zone 4, such as Seattle, would have a net decrease under all scenarios; however, other cities in this climate zone, such as Baltimore and New York, would have a net reduction only under the low emission scenario. The cities in Climate Zones 1-3 would have a net increase in source energy intensity under all three emission scenarios by the 2080 s.

This study also compared the energy analysis by the simplified degree day method with that by EnergyPlus simulations under the medium emission scenario in Atlanta, Miami, Minneapolis, and San Francisco. For cooling, as shown in Figure 5(a), the degree day method yielded results that were similar to those of the EnergyPlus simulations for Atlanta and Miami, but there was a large discrepancy for San Francisco. In a mild climate such as that of San Francisco, the cooling degree days are much more sensitive to the balance point temperature than in those cities that have a large cooling demand. Because this study selected $18.3^{\circ} \mathrm{C}\left(65^{\circ} \mathrm{F}\right)$ as the balance point temperature without regard to building type or climate, it may not accurately represent buildings in San Francisco. Another reason for the deviation is that the absolute value for cooling energy in 
San Francisco was small, and thus the relative value would be sensitive to even a very small change.

In the heating analysis, because Miami does not require heating most of the time, it was replaced by Minneapolis. The results obtained by the degree day method match reasonably well with those from the EnergyPlus simulations for cities with a large heating demand, as shown in Figure 5(b). In San Francisco, where a steady increase in cooling demand was observed (Figure 5(a)), the heating demand was found to fluctuate between 1960 and 2000 (Figure 5(b)). This latter trend was captured by both the degree day analysis and the energy simulation. A possible reason for the fluctuation in heating would be erratic weather occurrences such as winter storms and warm winter temperatures during that period of time. For example, California reportedly had several warm winters around the 2000s, which reduced heating demand. A comparison of the two energy analysis methods indicates that there are relatively small differences for buildings in hot or cold climates but a large deviation between the two methods in a mild climate.

Buildings interact with climates primarily through exterior walls, roofs, windows, ventilation systems, and infiltration. Buildings with a higher insulation level, larger core zone ratio, smaller window-to-wall ratio, and lower infiltration and outdoor air supply are be more isolated from outdoor conditions and thus would be less affected by climate change. For each building type, Tables 3 and 4 list important parameters that influence the impact of outdoor climate on the buildings.

Figure 6 compares the impact of climate change on cooling energy for different types of buildings in four cities by the 2080s under the medium emission scenario. Hospitals experience the smallest relative change in cooling energy even though hospital has large outdoor air requirement. There are two major reasons for this: 1) hospitals have large building internal load, such as interior equipment, lighting, which remain constant regardless of outdoor climate change, thus the relative change will be small; 2) the hospitals usually have large ratio of core zone to total floor area (85\% in this model) and small window-to-wall ratio $(16 \%)$, which could reduce the envelope loss. Restaurants suffer the most from global warming, primarily because all zones are exposed to the outdoors, as shown in Figure 1, and restaurants have the largest amount of 
outdoor air intake (7.14 ACH). Residential buildings such as single-family houses and apartments would have a relatively large increase in cooling energy because of their relatively low insulation level and high window U-factor as compared to commercial buildings. Strip-malls are also affected by climate change because all zones are fully exposed to the outdoors, and the air change rate is relatively high at $1.91 \mathrm{ACH}$. A comparison of medium and small office buildings shows that their cooling energy increases are generally comparable. Although medium offices have a larger ratio of core zone to total floor area, they have a higher window-to-wall ratio $(33 \%)$ than that of small office buildings $(20 \%)$. Furthermore, the building model for small offices has an unconditioned attic which shields the occupied zone from solar radiation and high outdoor temperatures during the summer. The impact of climate change on different types of buildings was influenced by multiple factors, and therefore integrated energy simulations would be more accurate than degree day analysis.

Climate change not only can affect the annual heating and cooling energy consumption, it also has impact on the peak energy use. Figure 7 shows the relative change in peak heating and cooling energy use for a single-family house under three emission scenarios in Chicago. It shows that the relative change in peak heating demand is less than cooling demand. One major reason is that the Coefficient of Performance (COP) of cooling equipment will decrease as outdoor temperature increases, while the boiler heating efficiency is independent of outdoor temperature. Thus, global warming not only increases the cooling load, but also reduces the COP of cooling equipment, thus increase the cooling energy use. It should be noted that neither TMY nor HadCM3 projection is sufficient to represent extreme weather conditions since extreme weather occurs more randomly and is hard to predict through GCM models. Therefore, it would be very likely that the future peak heating and cooling demand exceed the prediction in this paper on the event of sudden abnormal weather such as heat wave or cold storm.

This study also investigated the impact of climate change on the performance of natural ventilation for cooling. Among the cities studied, San Francisco, San Diego, and Seattle are the most suitable, and this paper discusses the results for single-family houses in these three cities. Since natural ventilation for cooling depends on outdoor conditions, it is expected that passive cooling performance will be greatly affected by global warming. We assumed that the indoor 
environment is too hot when the air temperature exceeds $26^{\circ} \mathrm{C}$. Figure 8 shows the percentage of time in each year when it was too hot indoors from the 1960s to the 2080s under the three emission scenarios. Figure 8(a) shows that in San Francisco, this percentage is always below 8\% even under the high emission scenario, and thus natural ventilation will still be suitable by the 2080s. For Seattle, natural ventilation would perform well under the low emission scenario. For San Diego, it would be too hot indoors for $30 \%$ of the time under the high emission scenario by the 2080s, which is more than 15 times higher than the percentage in the 2000s. Even under the low emission scenario, the indoor environment would be uncomfortable about $11 \%$ of the time. It can be concluded that natural ventilation and cooling would not be suitable by the end of the $21^{\text {st }}$ century in San Diego. Thus, for buildings that are designed to use natural ventilation in San Diego or Seattle, more thermal mass should be added to the buildings in order to counteract the effects of global warming.

To combat the global warming effect, it requires collaboration of designers, building owners and governments. The simplest method for building owners is to adjust the thermostat to use higher cooling setpoint and lower heating setpoint temperature. Also, adding more thermal mass during design phase for natural ventilated buildings would be beneficial since it would reduce the temperature fluctuation and serve as a buffer for a short period of extreme weather. The building code makers could increase the glazing material and envelope insulation requirement to reduce the envelope loss. Also, the ventilation requirement could be more flexible. For example, for advanced ventilation system such as displacement ventilation and underfloor air distribution system, which can provide better IAQ using the same amount of outdoor air due to their favorable air flow pattern[35], the ventilation requirement could be lower than traditional wellmixed system, which will reduce the ventilation load thus reduce building energy consumption.

\section{Conclusions}

This paper is the first to systematically investigate the impact of climate change on cooling and heating energy consumption in various types of buildings with different cooling modes by EnergyPlus in all 7 climate zones in the U.S. Future weather data was generated by the HadCM3 model for three $\mathrm{CO}_{2}$ scenarios and downscaled to hourly weather data by use of the Morphing method. An energy analysis was conducted with the EnergyPlus program for nine different types of buildings in 15 cities. This paper found that 
- HadCM3 model is capable for generating future TMY data for the U.S. and the accuracy is generally within $10 \%$ for projecting TMY2 to TMY3.

- By the 2080s, climate change would increase the annual temperature in the 15 cities by 2.3-7.0 $\mathrm{K}$ in comparison to that in the 1960s under the three emission scenarios;

- The majority of the cities located in Climate Zones 1-4 would experience a net increase in source energy use for cooling and heating by the 2080s, while cities in Climate Zones 6 and 7 would experience a net reduction in source energy use;

- The energy simulation showed that the impact of climate change varied greatly among different types of buildings; and

- By the 2080's, the effectiveness of natural ventilation would be greatly reduced by global warming in some cities, such as San Diego.

\section{Acknowledgement}

This research was funded partially by the Energy Efficient Building Hub led by the Pennsylvania State University through a grant from the U.S. Department of Energy and other government agencies, where Purdue University was a subcontractor to the grant.

\section{References}

[1] S. Solomon, D. Qin, M. Manning, Z. Chen, M. Marquis, K.B. Averyt, M. Tignor, H.L. Miller, Contribution of Working Group I to the Fourth Assessment Report of the Intergovernmental Panel on Climate Change, Cambridge, United Kingdom, Cambridge University Press, 2007.

[2] T.R. Karl, J.M. Melillo, T.C. Peterson, Global Climate Change Impacts in the United States, Cambridge University Press, Cambridge, United Kingdom, 2009.

[3] H. Radhi, Evaluating the potential impact of global warming on the UAE residential buildings - A contribution to reduce the $\mathrm{CO} 2$ emissions. Building and Environment 44 (2009) 2451-2462.

[4] D.H. Rosenthal, H. K. Gruenspecht, E. A. Moran, Effects of global warming on energy use for space heating and cooling in the United States, The Energy Journal 16 (1995) 77-96. 
[5] U.S. Department of Energy, Buildings Energy Data Book, Department of Energy, Washington DC, 2011.

[6] T.J. Wilbanks, Effects of Climate Change on Energy Production and Use in the United States, DIANE Publishing, Darby PA, 2009.

[7] D.J. Sailor, Relating residential and commercial sector electricity loads to climate: Evaluating state level sensitivities and vulnerabilities, Energy 26 (2001) 645-657.

[8] P.E. Levy, M.G. R. Cannell, A.D. Friend, Modelling the impact of future changes in climate, $\mathrm{CO}_{2}$ concentration and land use on natural ecosystems and the terrestrial carbon sink, Global Environmental Change 14 (2004) 21-30.

[9] J.M. Gregory, P.A. Stott, D.J. Cresswell, N.A. Rayner, C. Gordon, D.M.H. Sexton, Recent and future changes in Arctic sea ice simulated by the HadCM3 AOGCM, Geophysical Research Letters 29 (2002) 28-1-28-4.

[10] T.C. Johns, J.M. Gregory, W.J. Ingram, C.E. Johnson, A. Jones, J.A. Lowe, et al., Anthropogenic climate change for 1860 to 2100 simulated with the HadCM3 model under updated emissions scenarios, Climate Dynamics 20 (2003) 583-612.

[11] M. Collins, S.F.B. Tett, C. Cooper, The internal climate variability of HadCM3, a version of the Hadley Centre coupled model without flux adjustments, Climate Dynamics 17 (2001) 61-81.

[12] L.W. Baxter, K. Calandri, Global warming and electricity demand: A study of California, Energy Policy 20 (1992) 233-244.

[13] A.D. Amato, M. Ruth, P. Kirshen, J. Horwitz, Regional energy demand responses to climate change: Methodology and application to the Commonwealth of Massachusetts, Climatic Change 71 (2005) 175-201.

[14] M.J. Scott, D.L. Hadley, L.E. Wrench, Effects of climate change on commercial building energy demand, Energy Sources 16 (1994) 339-354.

[15] S.E. Belcher, J.N. Hacker, D.S. Powell, Constructing design weather data for future climates, Building Services Engineering Research and Technology 26 (2005) 49-61.

[16] M.F. Jentsch, S.B. AbuBakr, A.B.J. Patrick, Climate change future proofing of buildingsGeneration and assessment of building simulation weather files, Energy and Buildings 40 (2008) 2148-2168. 
[17] A.L.S. Chan, Developing future hourly weather files for studying the impact of climate change on building energy performance in Hong Kong, Energy and Buildings 43 (2011) 2860-2868.

[18] R.L. Smith, B.W. Xu, P. Switzer, Reassessing the relationship between ozone and shortterm mortality in US urban communities, Inhalation Toxicology 21 (2009) 37-61.

[19] Y.J. Huang, N. Miller, N. Schlegel, Effects of Global Climate Changes on Building Energy Consumption and Its Implications on Building Energy Codes and Policy in California: PIER Final Project Report, California Energy Commission, Berkeley, CA, 2009.

[20] Th. Frank, Climate change impacts on building heating and cooling energy demand in Switzerland, Energy and buildings 37 (2005) 1175-1185.

[21] X. Wang, D. Chen, Z. Ren, Assessment of climate change impact on residential building heating and cooling energy requirement in Australia, Building and Environment 45 (2010) 1663-1682.

[22] K. Wan, D. Li, W. Pan, J. Lam, Impact of climate change on building energy use in different climate zones and mitigation and adaptation implications, Applied Energy 97 (2012) 274-282.

[23] M. Olonscheck, A. Holsten, J. P. Kropp, Heating and cooling energy demand and related emissions of the German residential building stock under climate change, Energy Policy 39 (2011) 4795-4806.

[24] D.A. Asimakopoulos, M. Santamouris, I. Farrou, M. Laskari, M. Saliari, G. Zanis, G. Giannakidis et al., Modelling the energy demand projection of the building sector in Greece in the 21st century, Energy and Buildings 49 (2012) 488-498.

[25] ASHRAE Standard 90.1, Energy Standard for Buildings Except Low-Rise Residential Buildings, American Society of Heating, Refrigerating and Air-Conditioning Engineers, Inc., Atlanta GA, 2004.

[26] Department of Energy, EnergyPlus Engineering Reference: The Reference to EnergyPlus Calculations, Department of Energy, Washington, DC, 2010.

[27] ASHRAE Standard 62.1, Ventilation for Acceptable Indoor Air Quality, American Society of Heating, Refrigerating and Air-Conditioning Engineers, Inc., Atlanta GA, 2007. 
[28] ASHRAE Standard 62.2, Ventilation and Acceptable Indoor Air Quality for Low-Rise Residential Buildings, American Society of Heating, Refrigerating and Air-Conditioning Engineers, Inc., Atlanta GA, 2007.

[29] B.A. Thornton, M.I. Rosenberg, E.E. Richman, W. Wang, Y.L. Xie, J. Zhang, et al., Achieving the 30\% goal: Energy and cost savings analysis of ASHRAE Standard 90.12010. No. PNNL-20405, Pacific Northwest National Laboratory (PNNL), Richland, WA, 2011.

[30] V. Mendon, R. Lucas, S. Goel, Cost-effectiveness analysis of the 2009 and 2012 IECC residential provisions-Technical support document. Pacific Northwest National Laboratory (PNNL), Richland, WA, 2013.

[31] ASHRAE Standard 90.2, Energy Efficient Design of Low-Rise Residential Buildings, American Society of Heating, Refrigerating and Air-Conditioning Engineers, Inc., Atlanta GA, 2004.

[32] H. Wang and Q. Chen, A new empirical model for predicting single-sided, wind-driven natural ventilation in buildings, Energy and Buildings 54 (2012) 386-394.

[33] R. de Dear and G.S. Brager, The adaptive model of thermal comfort and energy conservation in the built environment, International Journal of Biometeorology 45 (2001) 100-108.

[34] M. Deru and P. Torcellini, Source energy and emission factors for energy use in buildings. Technical Report NREL/TP-550-38617, National Renewable Energy Laboratory, Golden CO, 2007.

[35] A. Novoselac and J. Srebric. A critical review on the performance and design of combined cooled ceiling and displacement ventilation systems, Energy and buildings 34 (2002) 497509. 


\section{List of figure captions}

Figure 1 3D rendering of building models used in EnergyPlus [29,30]

Figure 2 Comparison of predicted TMY3 data with actual TMY3 data (a) Dry-bulb temperature; (b) dew point temperature; (c) global horizontal solar radiation intensity

Figure 3 (a) Changes in annual temperature for the four selected cities under med emission scenario and (b) Changes in annual temperature for New York under three emission scenarios

Figure 4 Change in annual energy intensity under the three emission scenarios by the 2080s: (a) annual site energy intensity displayed separately for heating and cooling; (b) combined annual heating and cooling source energy intensity

Figure 5 Comparison of energy analysis by the degree day method with that by EnergyPlus (E+) simulations under the medium emission scenario: (a) cooling and (b) heating

Figure 6 Change in cooling energy for different types of buildings

Figure 7 Change in peak heating and cooling energy use for single-family house under three emission scenarios in Chicago

Figure 8 Percentage of time when the indoor air temperature is higher than $26^{\circ} \mathrm{C}$ with natural ventilation in (a) San Francisco, (b) Seattle, and (c) San Diego 

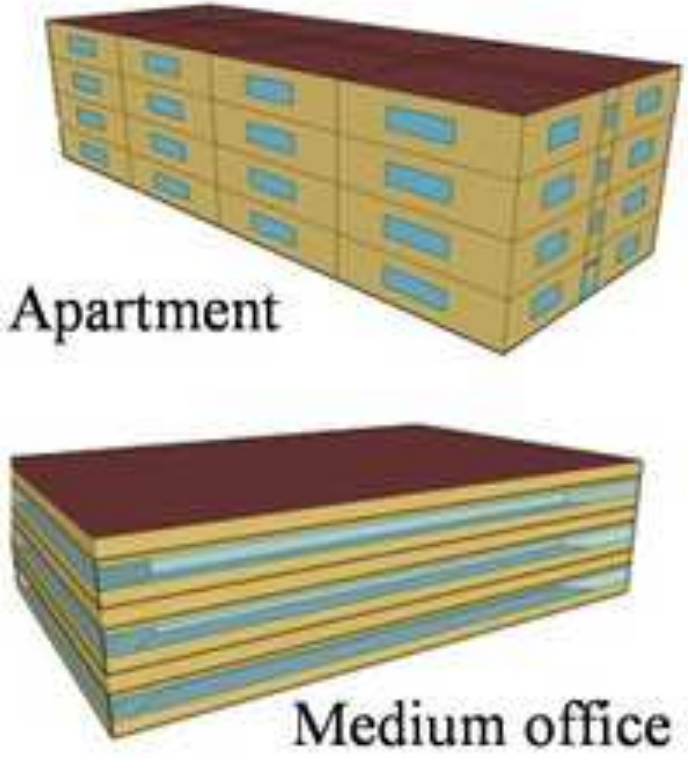

Single-family house

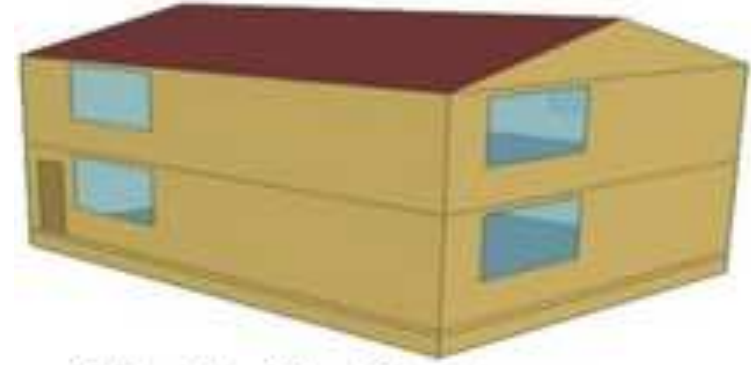

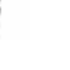

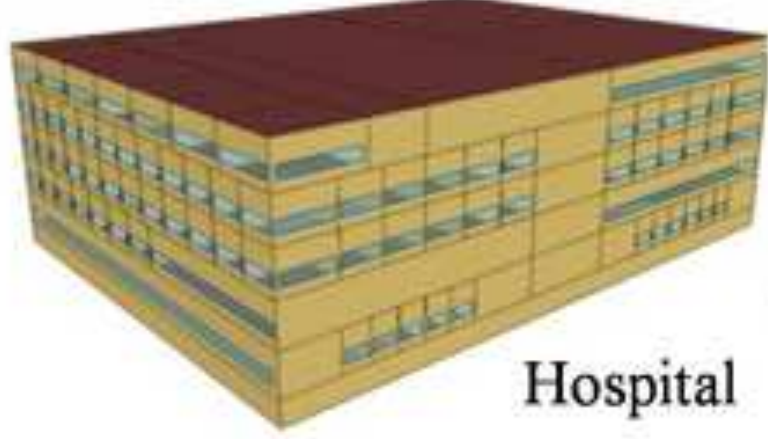

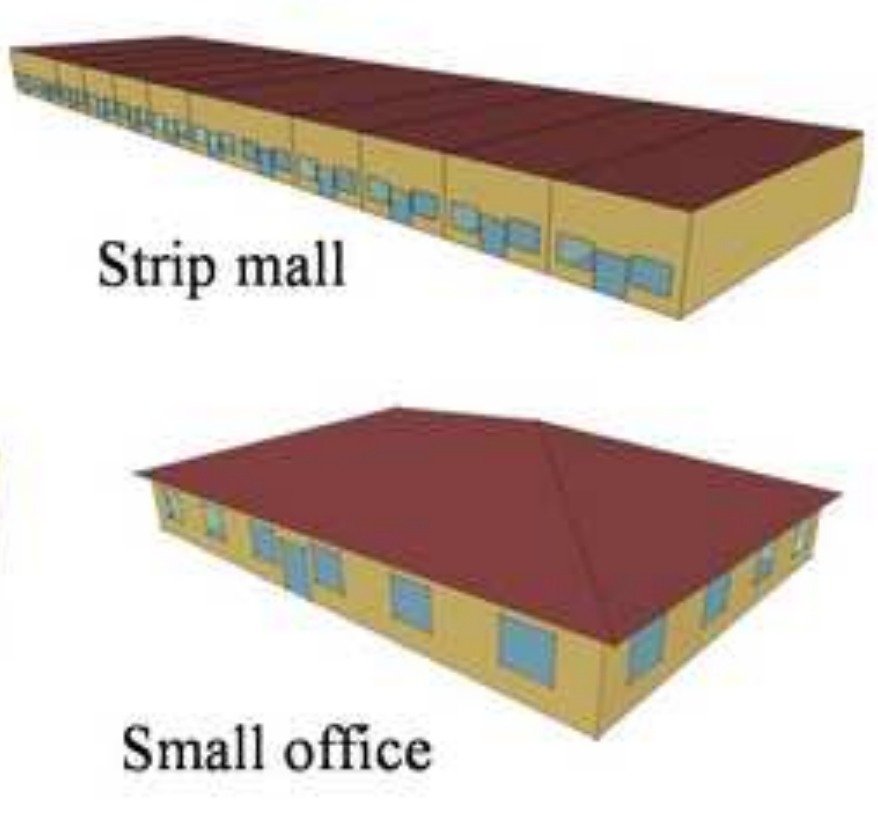

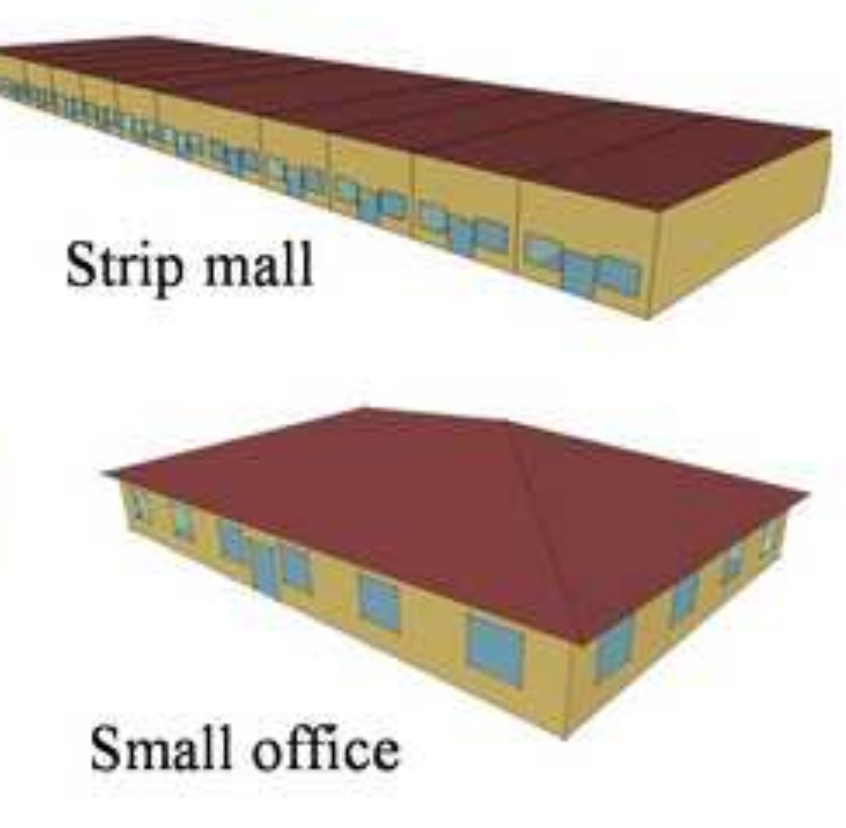

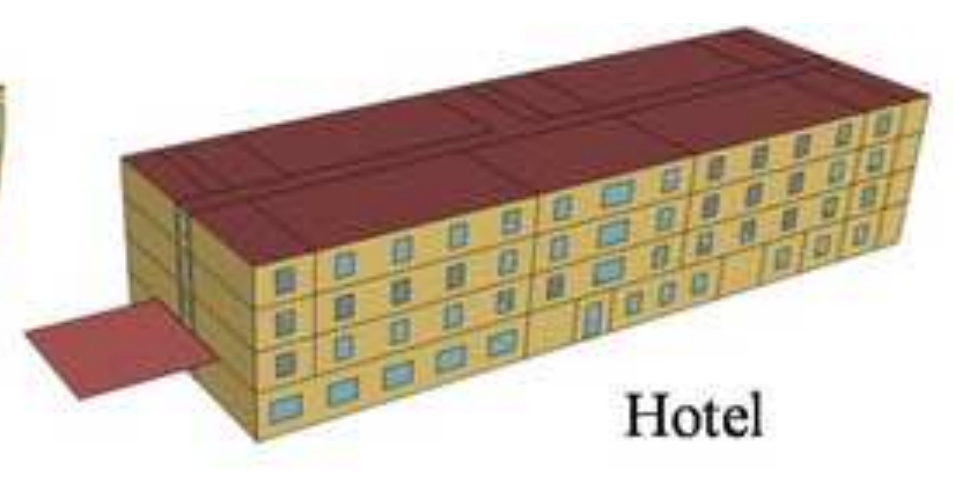

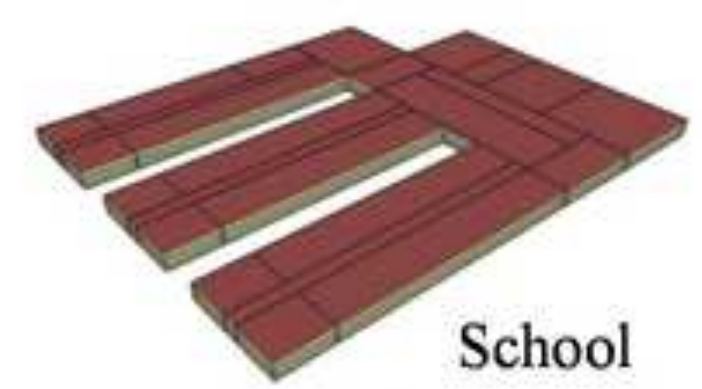

Restaurant

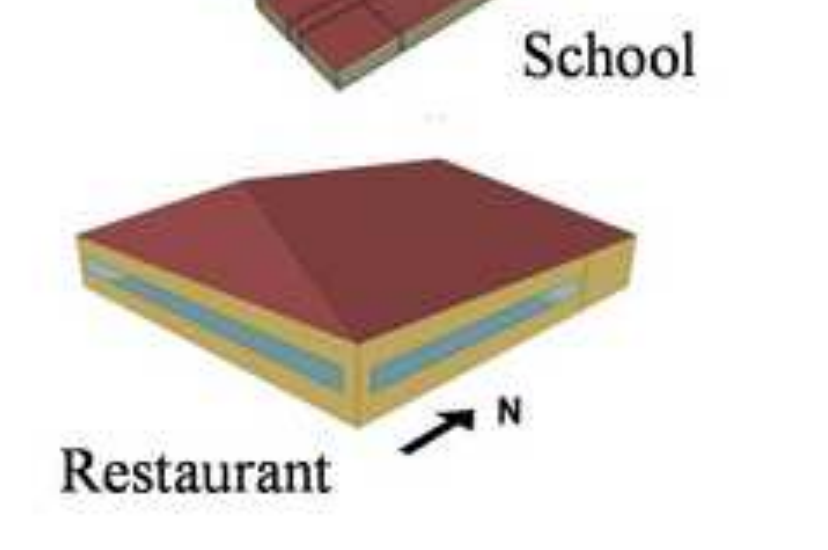




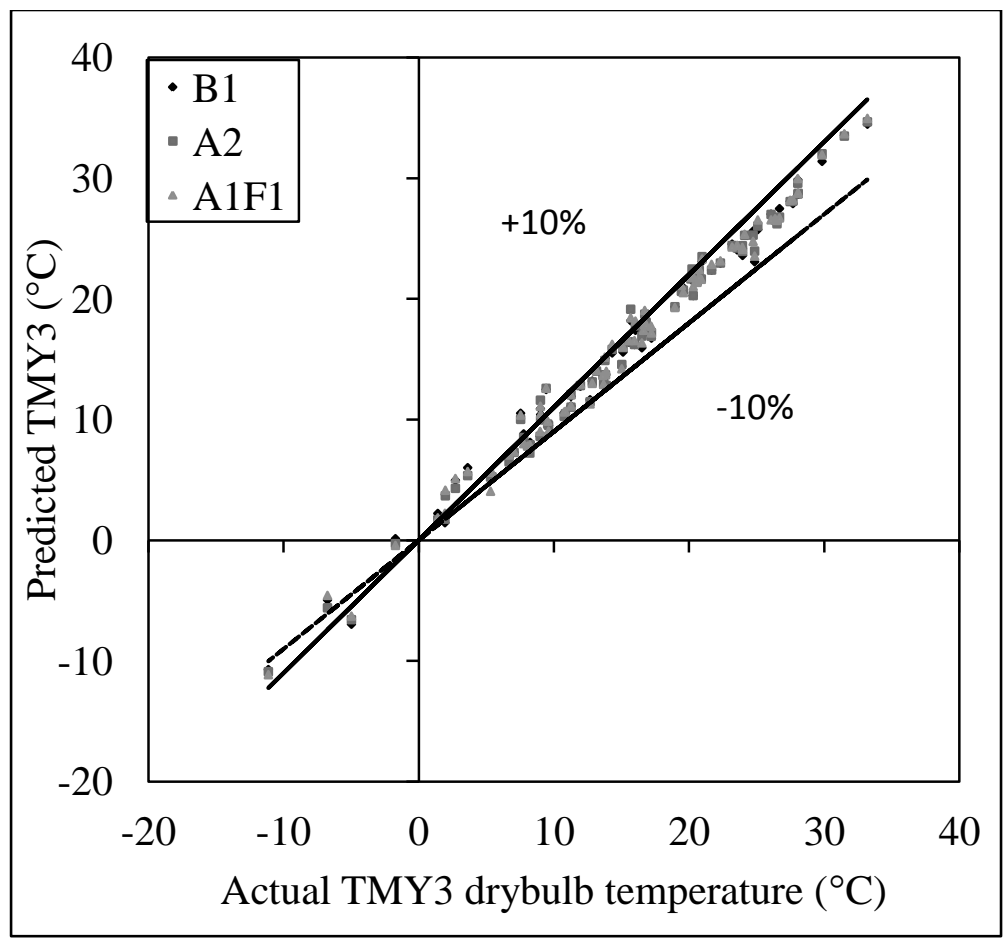

(a)

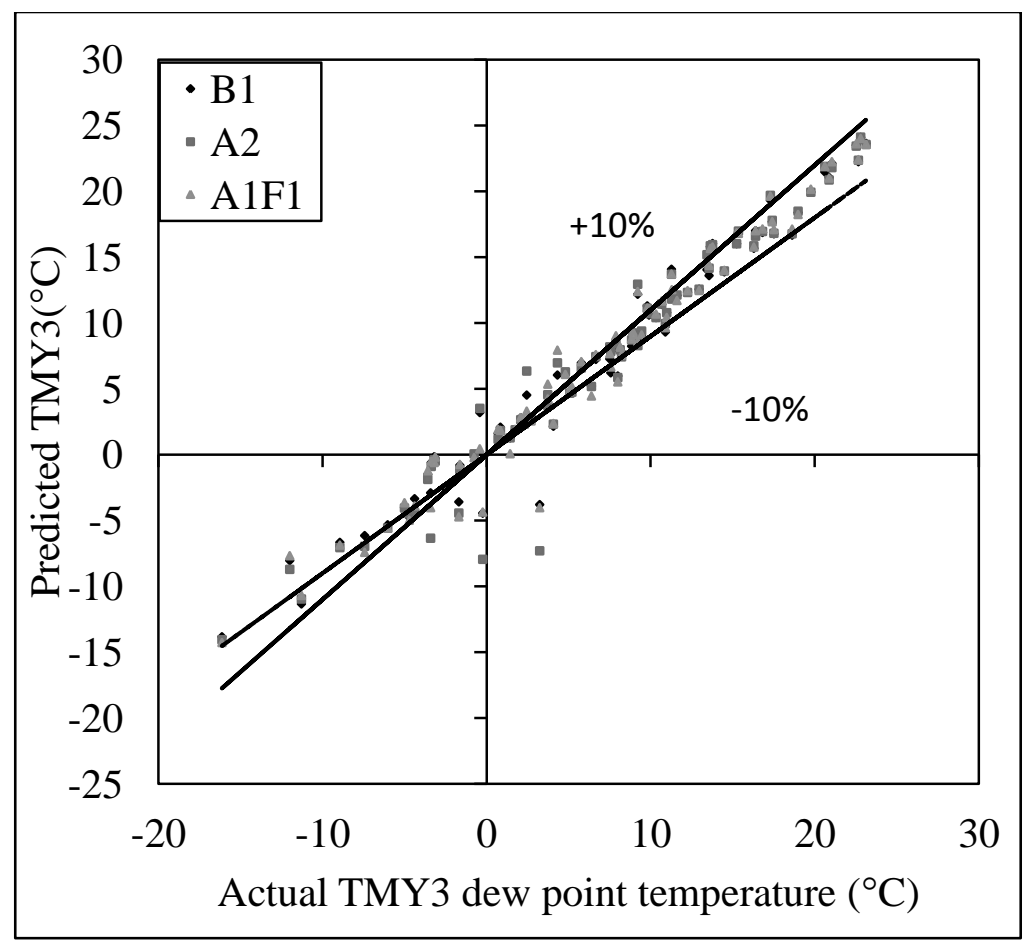

(b) 


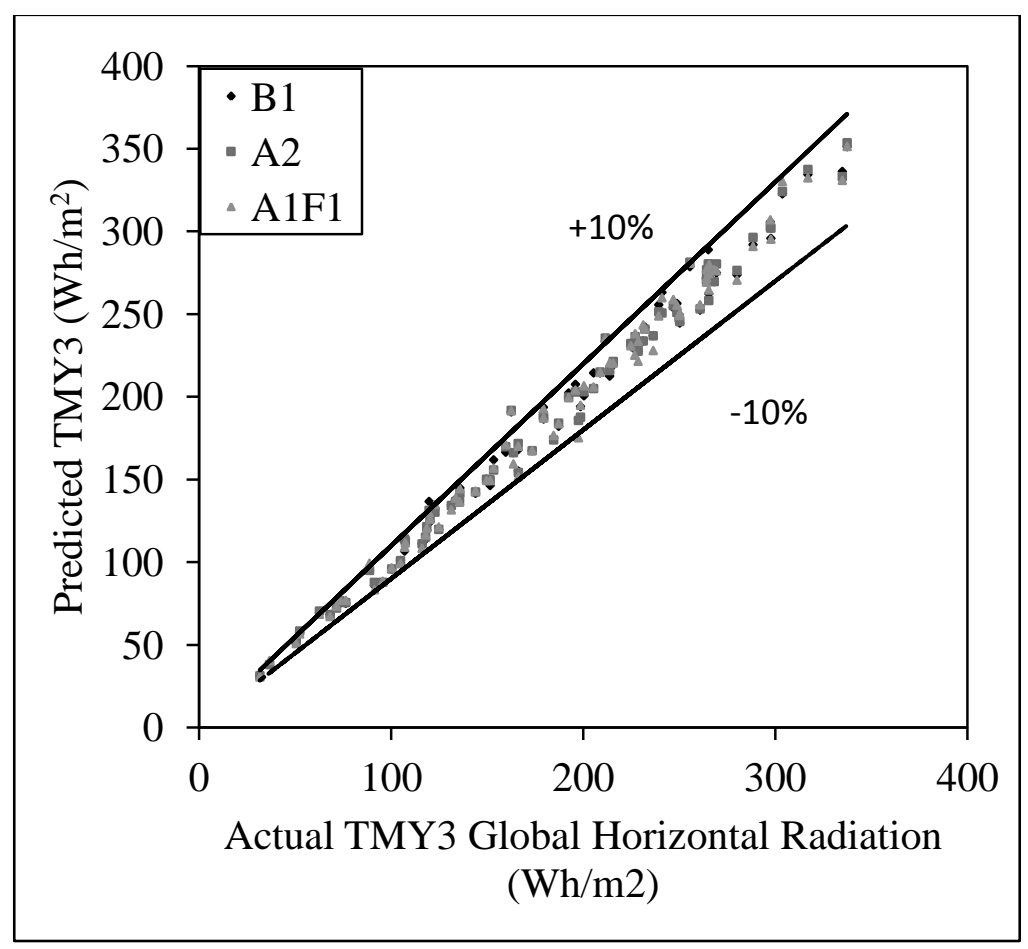

(c)

Figure 2 Comparison of predicted TMY3 data with actual TMY3 data (a) Dry-bulb temperature; (b) dew point temperature; (c) global horizontal solar radiation intensity 


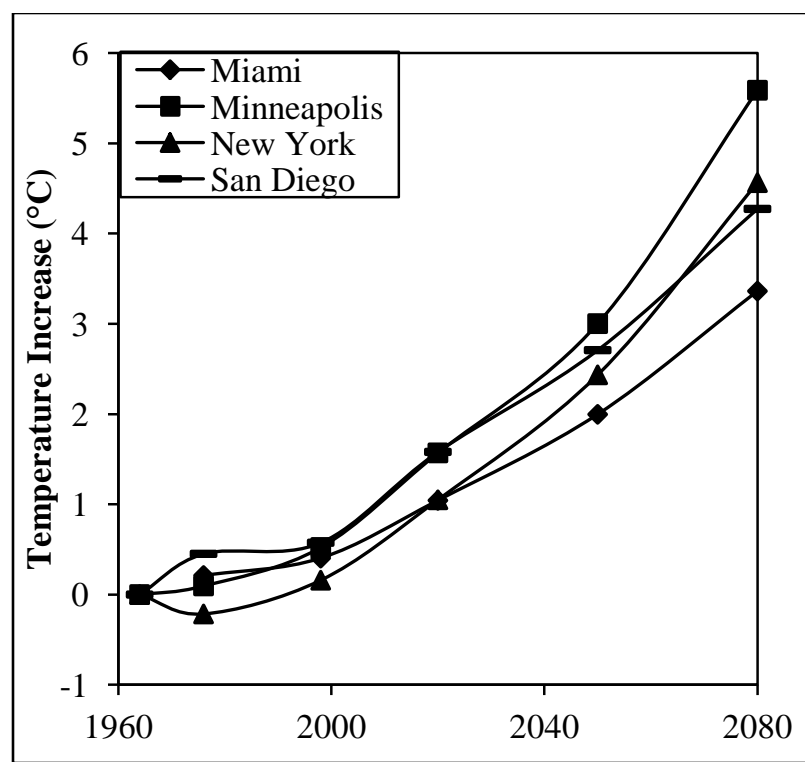

(a)

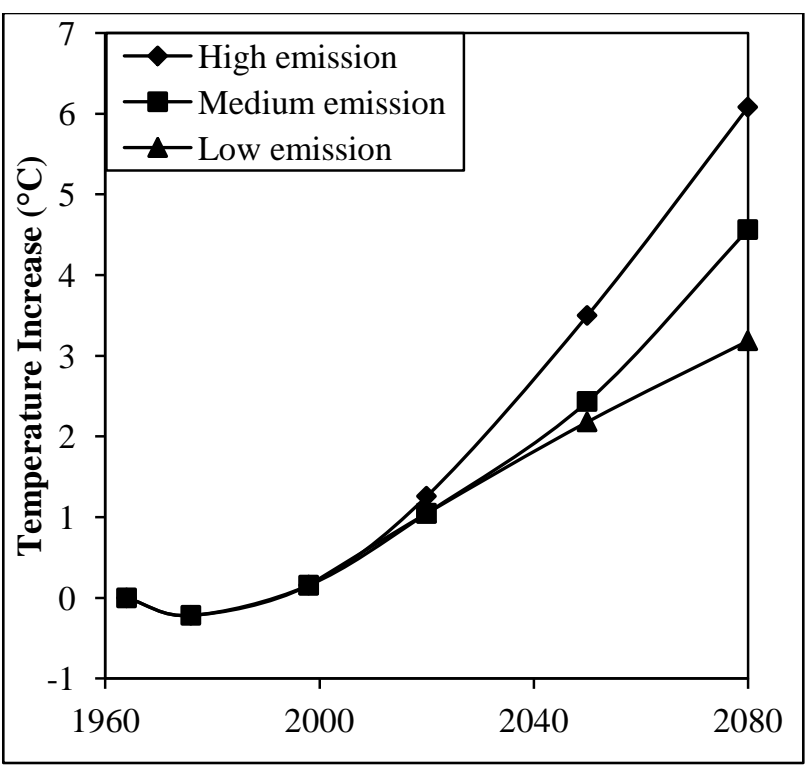

(b)

Figure 3 (a) Changes in annual temperature for the four selected cities under med emission scenario and (b) Changes in annual temperature for New York under three emission scenarios 


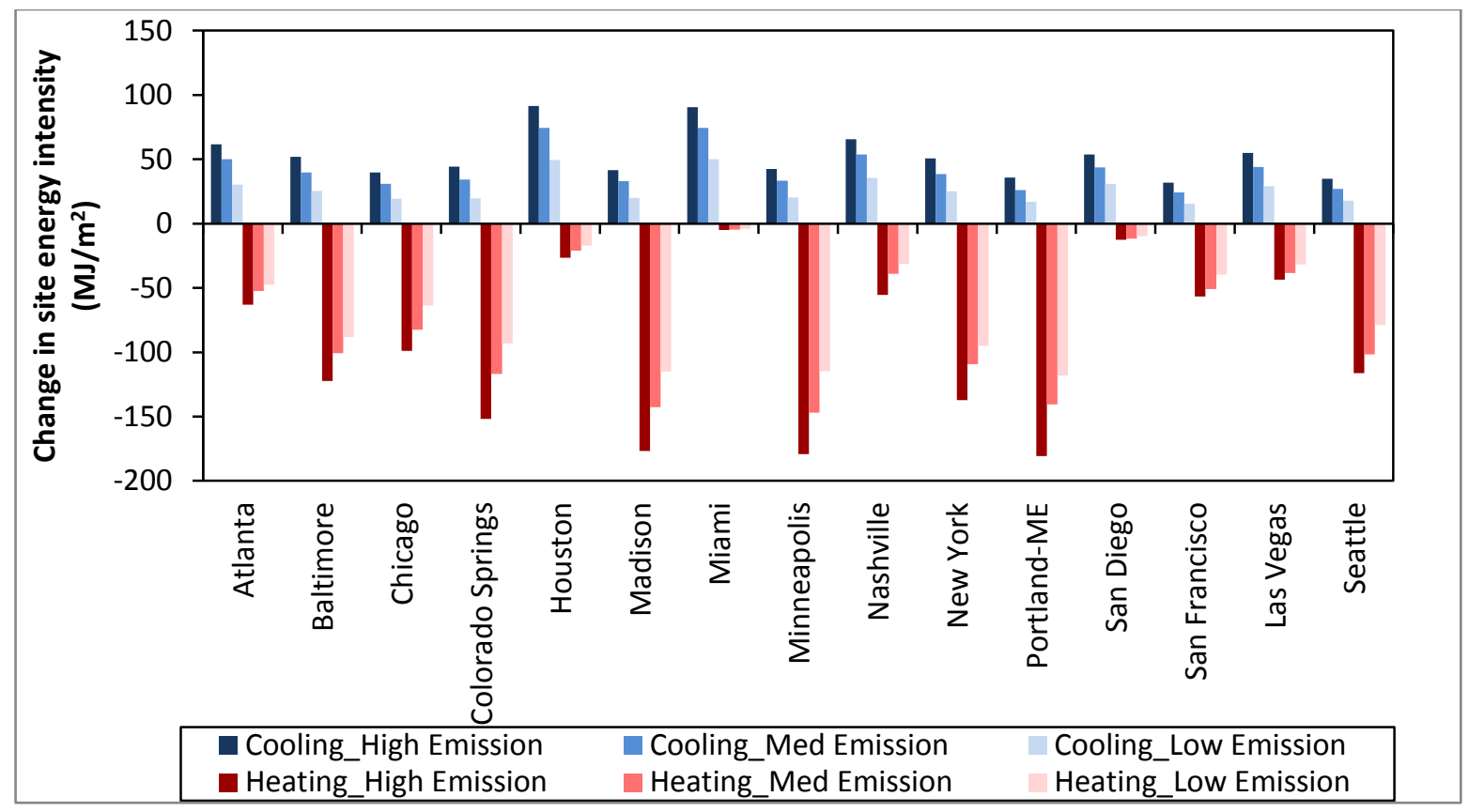

(a)

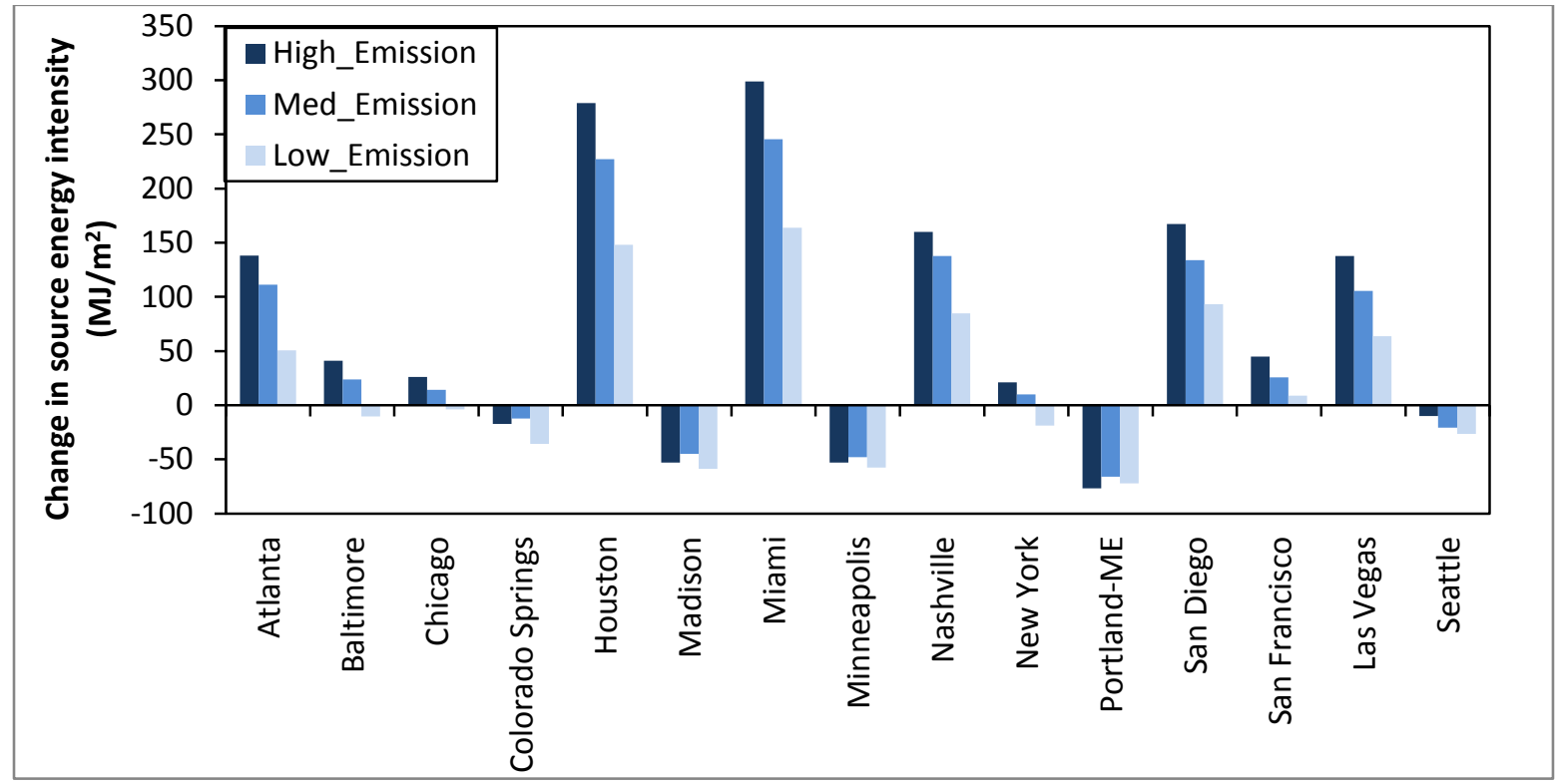

(b)

Figure 4 Change in annual energy intensity under the three emission scenarios by the 2080s: (a) annual site energy intensity displayed separately for heating and cooling; (b) combined annual heating and cooling source energy intensity 


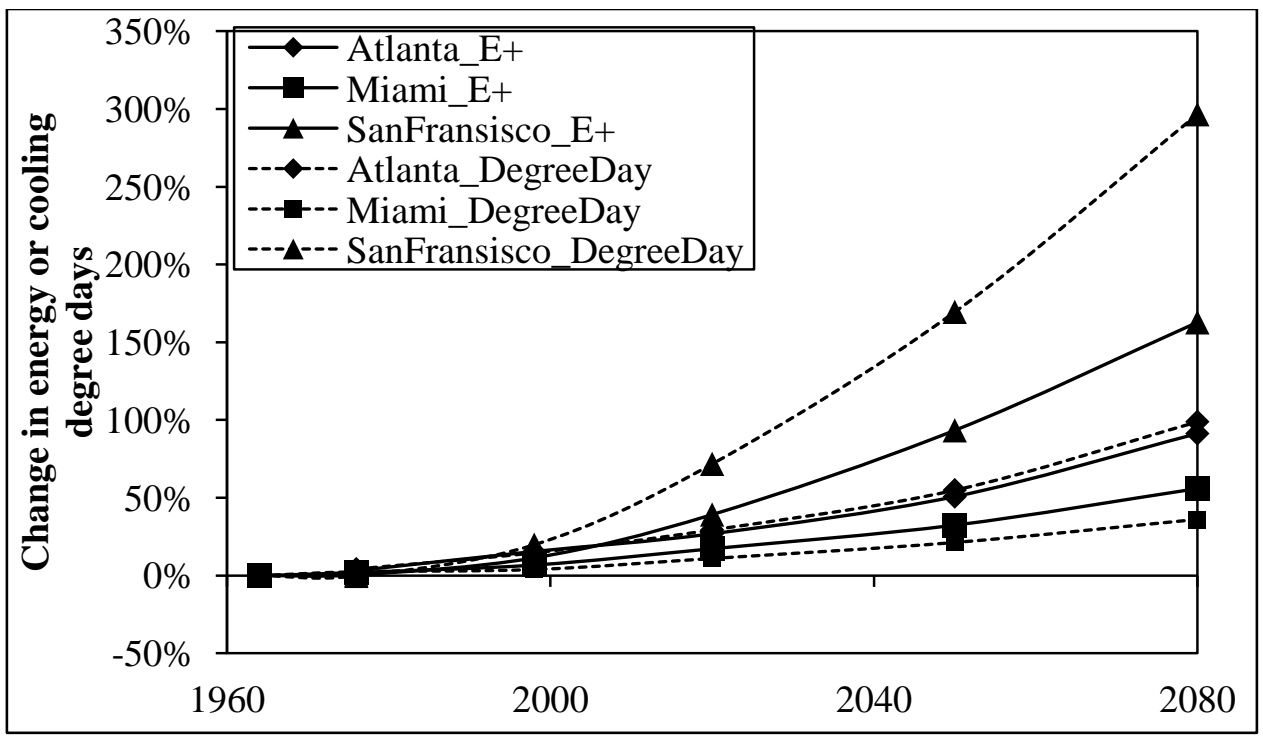

(a)

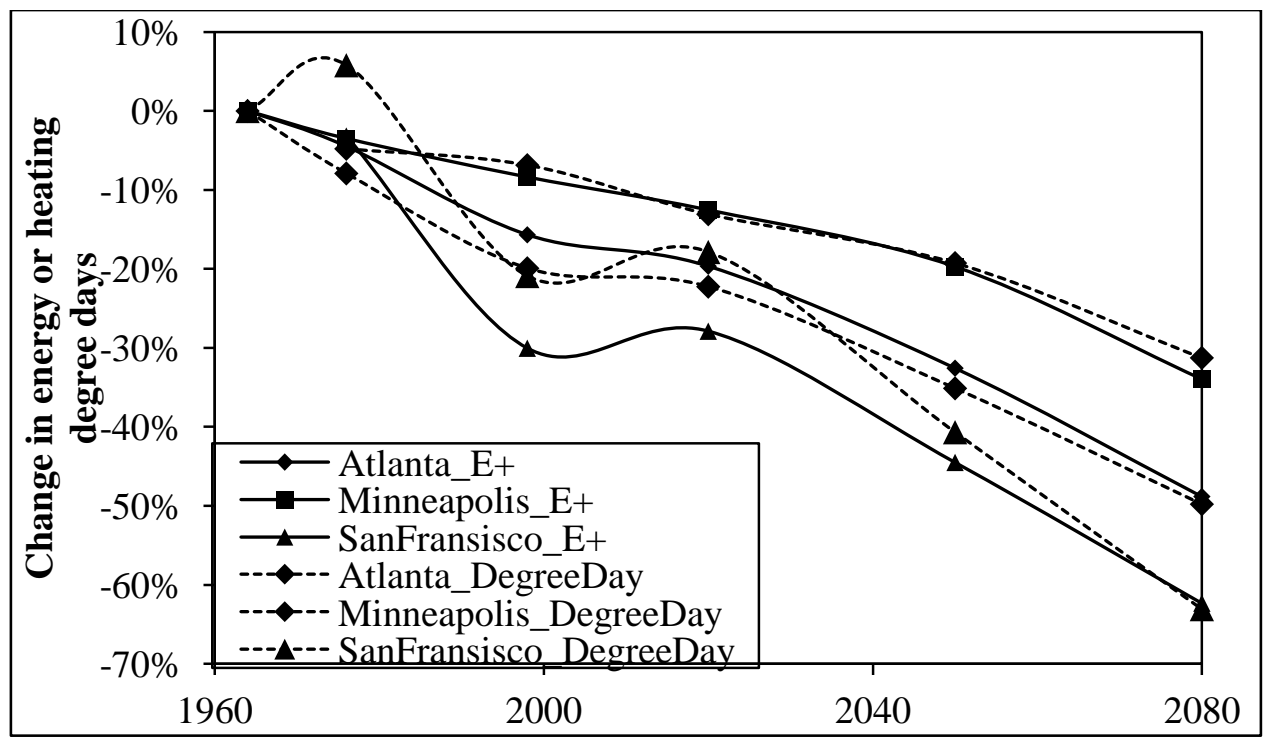

(b)

Figure 5 Comparison of energy analysis by the degree day method with that by EnergyPlus (E+) simulations under the medium emission scenario: (a) cooling and (b) heating 
Figure 6

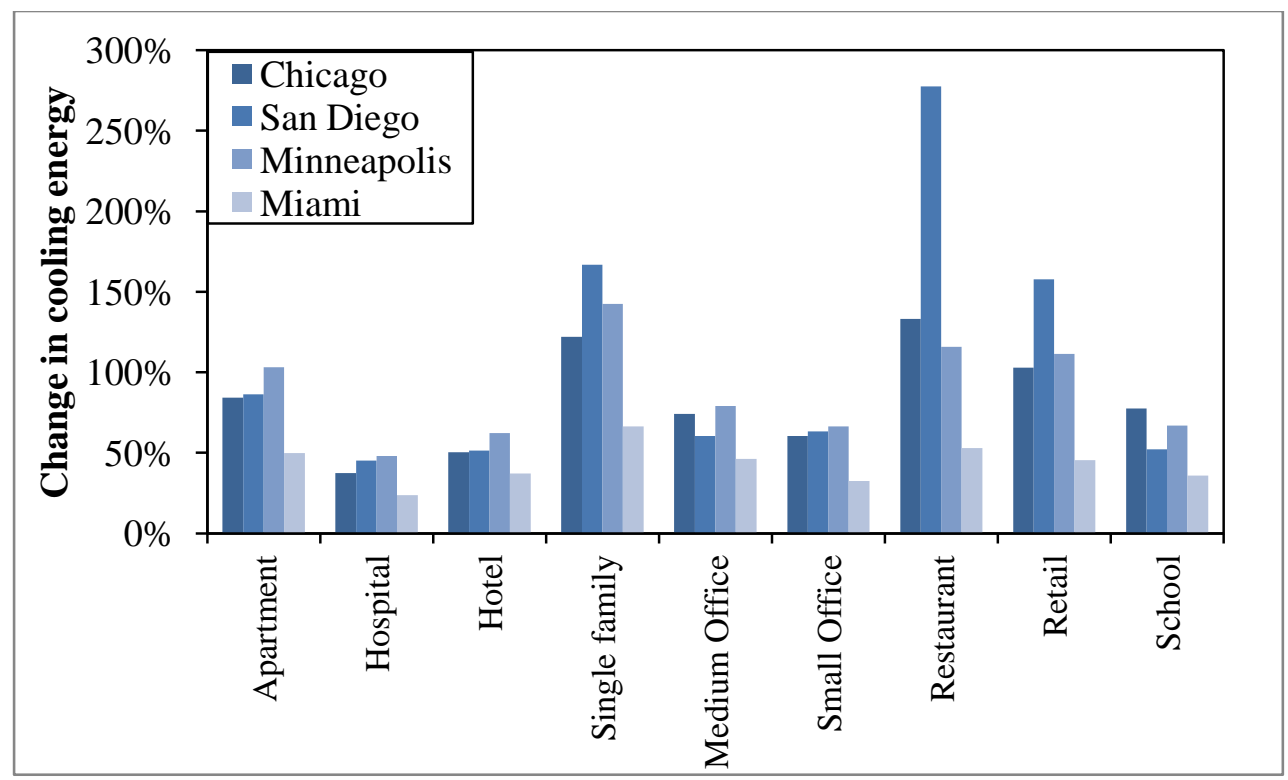

Figure 6 Change in cooling energy for different types of buildings 


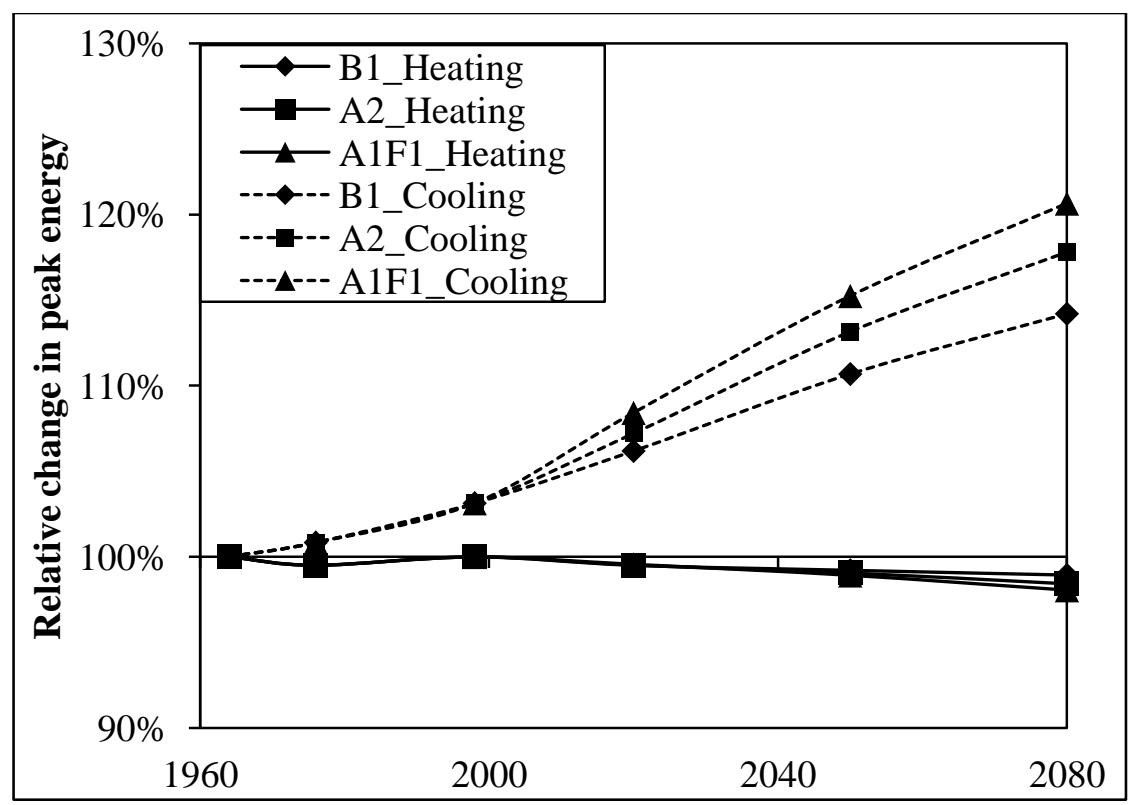

Figure 7 Change in peak heating and cooling energy use for single-family house under three emission scenarios in Chicago 


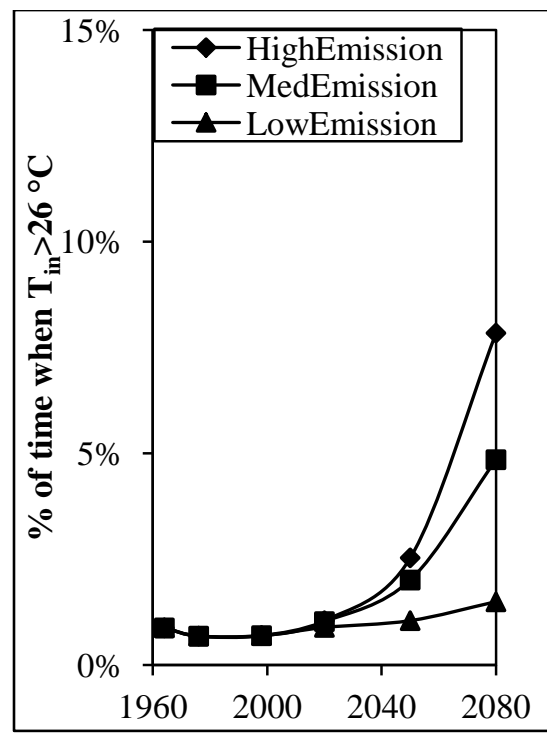

(a)

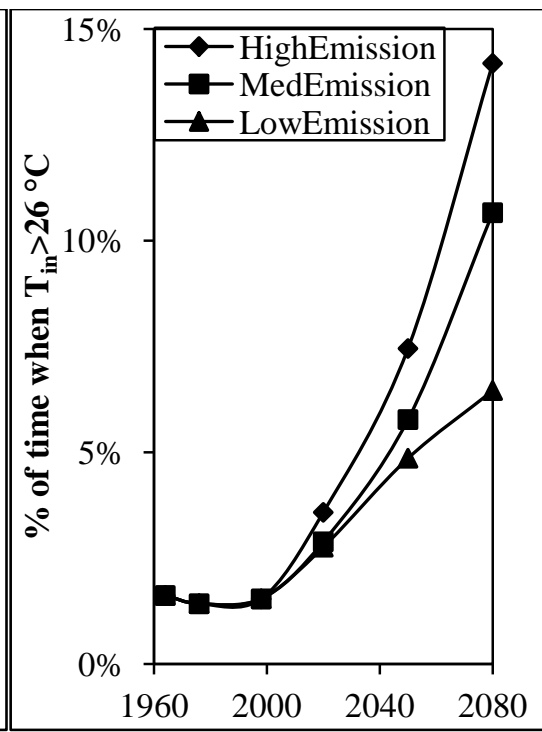

(b)

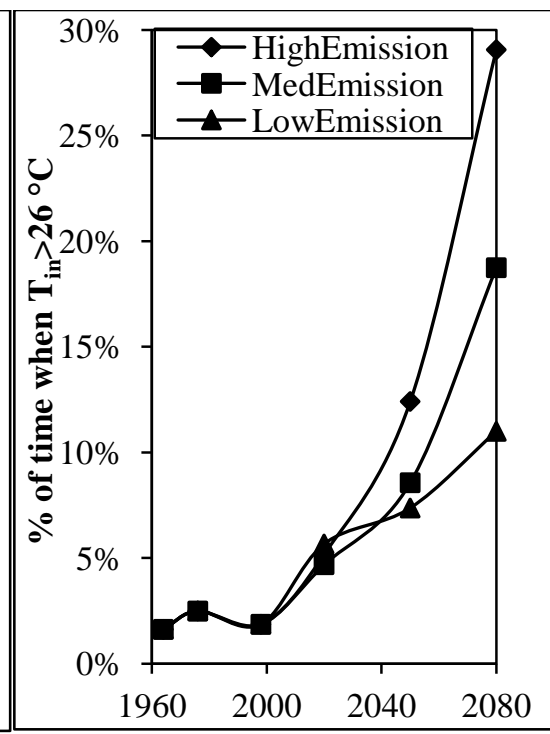

(c)

Figure 8 Percentage of time when the indoor air temperature is higher than $26^{\circ} \mathrm{C}$ with natural ventilation in (a) San Francisco, (b) Seattle, and (c) San Diego 
Table 1 Summary of previous literature on climate change impact on building heating and cooling energy use

\begin{tabular}{|c|c|c|}
\hline Author & Method & Major conclusion \\
\hline Rosenthal et al. [4] & $\begin{array}{l}\text { Residential and commercial in the U.S. Assume } \\
1^{\circ} \mathrm{C} \text { increase by } 2010 \text {. Degree day method. }\end{array}$ & $\begin{array}{l}1^{\circ} \mathrm{C} \text { increase will reduce energy } \\
\text { cost by } \$ 5.5 \text { billion in total U.S. } \\
\text { building stock }\end{array}$ \\
\hline Amato et al. [13] & $\begin{array}{l}\text { Residential and commercial in Massachusetts, } \\
\text { U.S. Canadian CGCM1 \& HadCM2 for weather } \\
\text { projection. Degree day method. }\end{array}$ & $\begin{array}{l}1.2-2.1 \% \text { increase in electricity, } 7- \\
14 \% \text { decrease in gas }\end{array}$ \\
\hline Scott et al. [14] & $\begin{array}{l}\text { Small office building in } 4 \text { cities in the U.S. } \\
\text { Assumed } 3.9^{\circ} \mathrm{C} \text { temperature increase with and } \\
\text { without humidity change. DOE-2 for building } \\
\text { simulation }\end{array}$ & $\begin{array}{l}\text { Humidity has large impact on } \\
\text { building energy projection. }\end{array}$ \\
\hline Jentsch et al. [16] & $\begin{array}{l}\text { An office building in Southampton, U.K. } \\
\text { HadCM3 projection with Morphing } \\
\text { downscaling. TRNSYS for building simulation }\end{array}$ & $\begin{array}{l}\text { Validated the Morphing method. } \\
\text { Case study shows natural } \\
\text { ventilation still available until } 2050 \\
\text { for the studied building. }\end{array}$ \\
\hline Chan [17] & $\begin{array}{l}\text { Apartment and office building in Hong Kong. } \\
\text { MIRCO3_2_MED for weather projection, } \\
\text { morphing for downscaling. EnergyPlus for } \\
\text { building simulation. }\end{array}$ & $\begin{array}{l}2.6-14.3 \% \text { for office building; } 3.7- \\
24 \% \text { for residential building in } \mathrm{A} / \mathrm{C} \\
\text { energy increase }\end{array}$ \\
\hline Huang et al. [19] & $\begin{array}{l}\text { Commercial buildings in California, U.S. } \\
\text { HadCM3 for weather projection. Morphing for } \\
\text { downscaling. DOE } 2.1 \text { for building simulation. }\end{array}$ & $\begin{array}{l}\text { Cooling electricity increased by } \\
50 \% \text { by } 2100 \text { under A1F1, 25\% for } \\
\text { A2. Peak cooling }\end{array}$ \\
\hline Radhi [3] & $\begin{array}{l}\text { Residential building in } \mathrm{Al} \text { Ain, UAE. Assumed } \\
1.6 \text { to } 5.9^{\circ} \mathrm{C} \text { temperature increase. Visual DOE } \\
\text { for building simulation. }\end{array}$ & $23.5 \%$ cooling electricity increase \\
\hline Frank [20] & $\begin{array}{l}\text { Residential and office buildings in Zurich- } \\
\text { Kloten, Switzerland. Assume } 0.7-4.4{ }^{\circ} \mathrm{C} \\
\text { temperature increase. HELLIOS for building } \\
\text { simulation. }\end{array}$ & $\begin{array}{l}36-58 \% \text { decrease in heatind } \\
\text { demand and } 220-1050 \% \text { increase } \\
\text { for cooling demand }\end{array}$ \\
\hline Wang et al. [21] & $\begin{array}{l}\text { Residential in five regions in Australia. } 9 \text { GCM } \\
\text { models. Morphing for downscaling. AccuRate } \\
\text { for building simulation. }\end{array}$ & $\begin{array}{l}\text { Total energy change }-48 \% \text { to } 350 \% \\
\text { by } 2100 .\end{array}$ \\
\hline Wan et al. [22] & $\begin{array}{l}\text { Office in five cities in China. MIROC } 3.2-\mathrm{H} \text { for } \\
\text { weather projection. VisualDOE4.1 for building } \\
\text { simulation. }\end{array}$ & $\begin{array}{l}11-20 \% \text { increase in cooling energy } \\
\text { and } 13-55 \% \text { decrease in heating } \\
\text { energy. }\end{array}$ \\
\hline Olonscheck et al. [23] & $\begin{array}{l}\text { Residential building in Germany. Assume } 1-3{ }^{\circ} \mathrm{C} \\
\text { temperature increase. Degree day method. }\end{array}$ & $\begin{array}{l}44-75 \% \text { decrease in heating. } 28- \\
59 \% \text { increase in cooling }\end{array}$ \\
\hline Asimakopoulos et al. [24] & $\begin{array}{l}3 \text { types of buildings in Greece. } 12 \text { Regional } \\
\text { Climate Models for weather projection. } \\
\text { Morphing for downscaling. TRNSYS for } \\
\text { building simulation }\end{array}$ & $\begin{array}{l}50 \% \text { decrease in heating, } 248 \% \\
\text { increase in cooling demand by } \\
2100 \text {. }\end{array}$ \\
\hline
\end{tabular}


Table 2 Cities investigated in this study and their climate zones

\begin{tabular}{|l|l|c|l|}
\hline City & State & Climate zone & Climate characteristics \\
\hline Atlanta & Georgia & 3A & Warm humid \\
\hline Baltimore & Maryland & 4A & Mixed humid \\
\hline Chicago & Illinois & 5A & Cold \\
\hline Colorado Springs & Colorado & 5B & Cold \\
\hline Houston & Texas & 2A & Hot humid \\
\hline Las Vegas & Nevada & 3B & Warm dry \\
\hline Madison & Wisconsin & 6A & Cold \\
\hline Miami & Florida & 1A & Hot humid \\
\hline Minneapolis & Minnesota & 7A & Very cold \\
\hline Nashville & Tennessee & 3A & Mixed humid \\
\hline New York City & New York & 4A & Mixed humid \\
\hline Portland & Maine & 6A & Cold \\
\hline San Diego & California & 3C & Marine \\
\hline San Francisco & California & 3C & Marine \\
\hline Seattle & Washington & 4C & Mixed marine \\
\hline
\end{tabular}


Table 3 Types of buildings studied in this paper and selected information [5, 29, 30]

\begin{tabular}{|c|c|c|c|c|c|c|c|c|c|}
\hline & $\begin{array}{l}\text { Total } \\
\text { floor } \\
\text { area in } \\
\text { U.S. }\end{array}$ & $\begin{array}{c}\text { Floor } \\
\text { area of } \\
\text { building } \\
\text { model }\end{array}$ & $\begin{array}{l}\text { Mechanical } \\
\text { Ventilation }\end{array}$ & Infiltration** & $\begin{array}{c}\text { Total } \\
\text { outdoor } \\
\text { air }\end{array}$ & $\begin{array}{l}\text { Occupied } \\
\text { hours }\end{array}$ & $\begin{array}{l}\text { Perimeter } \\
\text { zone } \\
\text { percentage }\end{array}$ & $\begin{array}{c}\text { Window- } \\
\text { to-wall } \\
\text { ratio }\end{array}$ & Attic \\
\hline Unit & $\begin{array}{c}\times 10^{6} \\
\mathrm{~m}^{2}\end{array}$ & $\mathrm{~m}^{2}$ & $\mathrm{ACH}$ & $\mathrm{ACH}$ & $\mathrm{ACH}$ & & & & \\
\hline Apartment & 5,232 & 3,135 & 0.37 & 0.26 & 0.63 & All day & $100 \%$ & $15 \%$ & No \\
\hline Hospital & 146 & 22,422 & 3.2 & 0.15 & 3.35 & All day & $<30 \%$ & $16 \%$ & No \\
\hline Hotel & 512 & 4,013 & 0.67 & 0.12 & 0.79 & All day & $<30 \%$ & $11 \%$ & No \\
\hline $\begin{array}{l}\text { Single } \\
\text { family } \\
\text { youse } \\
\end{array}$ & 16,886 & 223 & 0 & 0.45 & 0.45 & All day & $100 \%$ & $17 \%$ & Yes \\
\hline $\begin{array}{l}\text { Medium } \\
\text { Office }\end{array}$ & $659 *$ & 4,982 & 1.2 & 0.19 & 1.39 & $\begin{array}{l}7: 00- \\
22: 00\end{array}$ & $40 \%$ & $33 \%$ & No \\
\hline $\begin{array}{l}\text { Small } \\
\text { Office }\end{array}$ & $659 *$ & 511 & 0.47 & 0.34 & 0.81 & $\begin{array}{l}7: 00- \\
22: 00\end{array}$ & $70 \%$ & $21 \%$ & Yes \\
\hline Restaurant & 220 & 511 & 6.23 & 0.91 & 7.14 & $\begin{array}{l}6: 00- \\
24: 00\end{array}$ & $100 \%$ & $17 \%$ & No \\
\hline Mall & 1,098 & 2,090 & 1.37 & 0.54 & 1.91 & $\begin{array}{l}9: 00- \\
23: 00\end{array}$ & $100 \%$ & $10 \%$ & No \\
\hline School & 952 & 6,871 & 2.4 & 0.061 & 2.46 & $\begin{array}{c}\text { 7:00- } \\
21: 00 \\
\text { during } \\
\text { weekdays }\end{array}$ & $<30 \%$ & $35 \%$ & No \\
\hline
\end{tabular}

*Because the energy data book [5] does not provide the floor areas for small and medium office buildings separately, this study has assumed that the floor areas of small and medium office building are the same.

** The infiltration rate will be $25 \%$ of the value in the table during occupied hours due to the use of mechanical ventilation except singlefamily house 
Table 4 Building envelope and load information

\begin{tabular}{|c|c|c|}
\hline & Commercial Building & Residential \\
\hline Exterior Wall & $\begin{array}{l}\text { Hospital: } \\
\text { 200mm Normal weight concrete wall } \\
\text { Insulation* } \\
13 \mathrm{~mm} \text { Gypsum } \\
\\
\text { The rest of commercial buildings: } \\
25 \mathrm{~mm} \text { stucco } \\
16 \mathrm{~mm} \text { gypsum } \\
\text { Insulation* } \\
16 \mathrm{~mm} \text { gypsum }\end{array}$ & $\begin{array}{l}25 \mathrm{~mm} \text { stucco } \\
16 \mathrm{~mm} \text { gypsum } \\
\text { Insulation* } \\
16 \mathrm{~mm} \text { gypsum }\end{array}$ \\
\hline Roof & $\begin{array}{l}\text { 9.5mm Built-up roofing } \\
\text { Insulation* } \\
0.8 \mathrm{~mm} \text { Metal surface }\end{array}$ & $\begin{array}{l}\text { Apartment: Same as commercial buildings } \\
\text { Single-family house: } \\
3.2 \mathrm{~mm} \text { Asphalt shingles with ceiling } \\
\text { insulation* on the attic floor }\end{array}$ \\
\hline Exterior floor & $\begin{array}{l}\text { 200mm Normal weight concrete floor } \\
25 \mathrm{~mm} \text { Carpet pad }\end{array}$ & $\begin{array}{l}\text { Apartment: Same as commercial buildings } \\
\text { Single-family house: } \\
19 \mathrm{~mm} \text { Plywood } \\
25 \mathrm{~mm} \text { Carpet pad }\end{array}$ \\
\hline Interior wall & G01 26mm gypsum board & \\
\hline Interior floor & $\begin{array}{l}\text { 100mm Normal weight concrete floor } \\
25 \mathrm{~mm} \text { Carpet pad }\end{array}$ & $\begin{array}{l}\text { Apartment: Same as commercial buildings } \\
\text { Single-family house: } \\
19 \mathrm{~mm} \text { Plywood } \\
25 \mathrm{~mm} \text { Carpet pad }\end{array}$ \\
\hline Exterior window & \multicolumn{2}{|c|}{$\begin{array}{l}\text { Commercial buildings and apartment U value and solar heat gain coefficient based on ASHRAE } 90.1 \\
\text { [25] for each climate zone } \\
\text { Single family house based on ASHRAE } 90.2 \text { [31] }\end{array}$} \\
\hline Internal heat gain & \multicolumn{2}{|c|}{$\begin{array}{l}\text { For commercial buildings and apartment, please refer to Thornton et al. [29] for people, lighting, plug } \\
\text { load definitions and schedules } \\
\text { For single-family house, please refer to Mendon et al. [30] for people, lighting, plug load definitions } \\
\text { and schedules }\end{array}$} \\
\hline $\begin{array}{l}\text { Heating/cooling } \\
\text { setpoints }\end{array}$ & \multicolumn{2}{|c|}{$21 / 24^{\circ} \mathrm{C}$ Setback with $2.7^{\circ} \mathrm{C}$ during unoccupied hours } \\
\hline
\end{tabular}

*Insulation R-value is defined by ASHRAE Standards 90.1 [25] and 90.2 [31] for each climate zone 